\title{
Seismic analysis of soil nail performance in deep excavation
}

\author{
Md. Khaja Moniuddin ${ }^{1 *}$, P. Manjularani ${ }^{2}$ and L. Govindaraju ${ }^{3}$
}

\author{
${ }^{*}$ Correspondence: \\ mdkhajamoniuddin@gmail. \\ com \\ ${ }^{1}$ Department of Civil \\ Engineering, Bheemanna \\ Khandre Institute \\ of Technology, Bhalki, India \\ Full list of author information \\ is available at the end of the \\ article
}

\begin{abstract}
Deep excavation is a common part of development to utilize underground space in densely populated areas. Protection of contiguous building and properties is a primary design concern space. Soil nailing is one such technique to exchange conventional retaining system for deep excavation. It will also donate to significant saving in cost and time of construction compared to conventional retaining systems. In this study an attempt has been made to have a deep vertical excavation on ground of $10 \mathrm{~m}$ height using soil nail wall. Also studied the enactment of soil nail wall under different nail inclination to horizontal i.e., $\Theta=0^{\circ}$ and $\Theta=15^{\circ}$ with water table. The finite element analysis of soil nail wall was carried to study the behavior of maximum horizontal wall displacement, maximum horizontal nail displacement, base heave, maximum axial force in nail, maximum shear force in nail, maximum bending moment in nail under both static and seismic conditions using PLAXIS 2D. The process of construction is carried out in stages and a value of Global factor of safety $\left(\mathrm{FS}_{\mathrm{G}}\right)$ is maintained above 1.5 to make sure its stability. The length of nail has a major impact on the behavior of soil nail wall system; increase in nail length will increase the $\mathrm{FS}_{\mathrm{G}}$. Results of the numerical analysis direct that the use of soil nail wall is desirable to impart stability to retaining systems.
\end{abstract}

Keywords: Soil nail, Horizontal wall displacement, Base heave, Axial force in nail, Shear force, Bending moment

\section{Background}

Soil nailing is a method in which soil slopes, excavations or retaining wall are passively reinforced by the insertion of relatively slender elements-normally steel reinforcing bars [1]. Such structural element which offers load transfer to the ground in excavation reinforcement application is called nail. The fundamental concept of soil nailing relies upon two possible mechanisms, both of which donating to improve stability of soil mass: the transfer of tensile forces generated in the nails through frictional interaction between the ground and the soil nail, and the development of shear stress and bending stiffness in the nails as a result of deformation of soil mass [2]. In the accumulation to the aforementioned mechanisms, the soil structure interaction between the facing and the soil helps to restrain displacement, limit decompression during and after excavation, and produce nail head load at the connection between the nail and the facing necessary to develop the force along the nail. The long term performance of soil nailed excavations 
is a major unknown to those designing the soil nail systems because there are very few over 20 years old [3].

\section{Modeling and analysis}

"PLAXIS version 8.2" is two-dimensional finite element code and is available commercially to conduct analysis of deformation and stability for a variety of geotechnical problems. The program can be castoff in plane strain as well as in axisymmetric modelling (Fig. 1). The program can also be used to model slope-stability problems and uses a Phi$c$ reduction routine for calculating the factor of safety. With its advanced built- in soil models, it provides tools to simulate systems of real events:

- Change in geometry (excavation, fill placement)

- Change in soil properties (fill replacement).

\section{Material parameters}

The material parameters considered for the analysis of the soil are tabulated in Table 1 [4].

\section{Calculation of axial stiffness (EA) and bending stiffness (EI)}

For the grouted nails, equivalent modulus of elasticity $\mathrm{E}_{\mathrm{eq}}$ shall be determined accounting for the contribution of elastic stiffness of both grout cover as well as reinforcement bar [4]. From the fundamentals of strength of materials, $\mathrm{E}_{\mathrm{eq}}$ can be determined as

$$
E_{e q}=E_{n}\left(\frac{A_{n}}{A}\right)+E_{g}\left(\frac{A_{g}}{A}\right)
$$

where: $E_{g}$ : modulus of elasticity of grout, $E_{n}$ : modulus of elasticity of nail, $E_{e q}$ : equivalent modulus of elasticity of grouted soil nail, $A_{n}$ : cross-section area of reinforcement bar, $A_{g}$ : cross-section area of grout cover, A: cross-section area of grouted soil nail, $A=0.25 \pi D^{2}, A_{n}=0.25 \pi d^{2}, A=A-A_{n}$

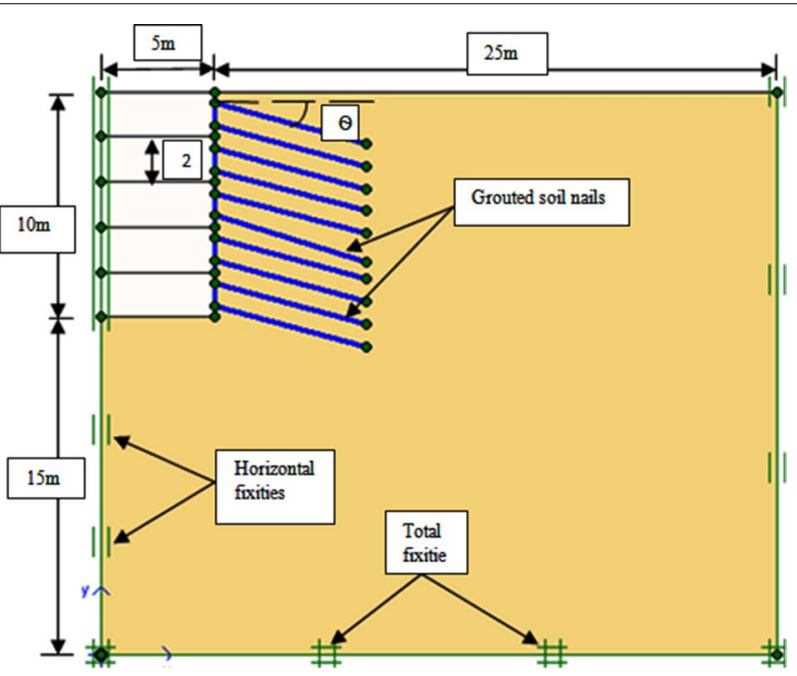

Fig. 1 Numerically simulated soil nail wall 


$$
\begin{aligned}
& \text { Axial stiffness EA }[\mathrm{kN} / \mathrm{m}]=\frac{\mathrm{Eeq}}{\mathrm{Sh}}\left(\frac{\pi \mathrm{D}^{2}}{4}\right) \\
& \text { Bending stiffness EI }\left[\mathrm{kNm}^{2} / \mathrm{m}\right]=\frac{\mathrm{Eeq}}{\mathrm{Sh}}\left(\frac{\pi \mathrm{D}^{4}}{64}\right)
\end{aligned}
$$

where, D: diameter of drill hole, d: diameter of nail. Below table gives values of EA and EI calculated ung the formulas given in the above equation (Tables 1, 2, 3).

\begin{tabular}{|c|c|}
\hline Parameters & $\begin{array}{l}\text { Values } \\
\text { Soil }\end{array}$ \\
\hline Vertical height of wall H (m) & 10 \\
\hline Nail type & Grouted \\
\hline Simulation model & Plane strain \\
\hline Element type & 15 node \\
\hline \multicolumn{2}{|l|}{ In-situ soil } \\
\hline Material model & Mohr-coulomb \\
\hline Cohesion c (Kpa) & 4 \\
\hline Internal friction angle $\varnothing\{$ deg $\}$ & $31.5^{\circ}$ \\
\hline Unit weight $\gamma\left[\mathrm{KN} / \mathrm{m}^{3}\right]$ & 17 \\
\hline Elastic modulus $\mathrm{E}_{\mathrm{s}}[\mathrm{Mpa}]$ & 20 \\
\hline Poison's ratio of soil $v_{s}$ & 0.3 \\
\hline \multicolumn{2}{|l|}{ Grouted nails and facing } \\
\hline Yield strength $\mathrm{F}_{\mathrm{y}}[\mathrm{Mpa}]$ & 415 \\
\hline Elastic modulus $\mathrm{E}_{\mathrm{n}}$ [Gpa] & 200 \\
\hline Elastic modulus of grout (concrete) $\mathrm{E}_{\mathrm{g}}$ [Gpa] & 20 \\
\hline Diameter d [mm] & 20 \\
\hline Drill hole diameter $\mathrm{D}_{\mathrm{DH}}[\mathrm{mm}]$ & 100 \\
\hline Length of nail L [m] & $7,10,13,15$ \\
\hline Declination with respect to horizontal $\Theta$ [degree] & $0^{\circ}$ and $15^{\circ}$ \\
\hline Spacing $S_{h} \times S_{v}[m]$ & $1 \times 1$ \\
\hline Facing thickness $\mathrm{t}[\mathrm{mm}]$ & 200 \\
\hline
\end{tabular}

Table 1 Parameters used for numerical simulation [8]

Table 2 Material properties for grouted nail

\begin{tabular}{llll}
\hline Pameters & Name & Value & Unit \\
\hline Material type & - & Elastic & - \\
Axial stiffness & EA & $228.707 \times 10^{3}$ & $\mathrm{kN} / \mathrm{m}$ \\
Bending stiffness & El & 142.9419 & $\mathrm{kNm} 2 / \mathrm{m}$ \\
\hline
\end{tabular}

Table 3 Material properties for facing

\begin{tabular}{llll}
\hline Parameters & Name & Value & Unit \\
\hline Material type & - & Elastic & - \\
Axial stiffness & EA & $4.4 \times 10^{6}$ & $\mathrm{kN} / \mathrm{m}$ \\
Bending stiffness & El & 1466.74 & $\mathrm{kNm} 2 / \mathrm{m}$ \\
\hline
\end{tabular}




\section{Case studies carried out}

The following two cases are considered for Finite Element Analysis of the soil nail wall without water table are as shown below. Soil nails are placed horizontally i.e. $\Theta=0^{\circ}$ and at an inclination of $\Theta=15^{\circ}$ and the construction is carried out in stages at every increment of $20 \%$. Initially $2 \mathrm{~m}$ excavation is carried and followed by insertion of nails and facing, if stability is less, then the nail length is increased to achieve the factor of safety more than 1.5. Further another $2 \mathrm{~m}$ excavation is carried and the process is repeated until a depth of $10 \mathrm{~m}$.

\section{Case 1: soil without water table (WOW) having $\Theta=0^{\circ}$}

In Fig. 2, it can be seen that the length of the nail is increased at the final stage because the $\mathrm{FS}_{\mathrm{G}}$ decreases to 1.37 shown in Table 4, which is below 1.5. As per FHWA the least recommended $\mathrm{FS}_{\mathrm{G}}$ should be 1.5 [5]. To provide global stability, the soil nail should spread beyond the potential failure surface. The length of nail has a major impact on the behavior of soil nail wall system. The resistance against pull-out failure of the soil nails is provided by the part of soil nail that is entrenched into the ground behind the potential failure surface [6].

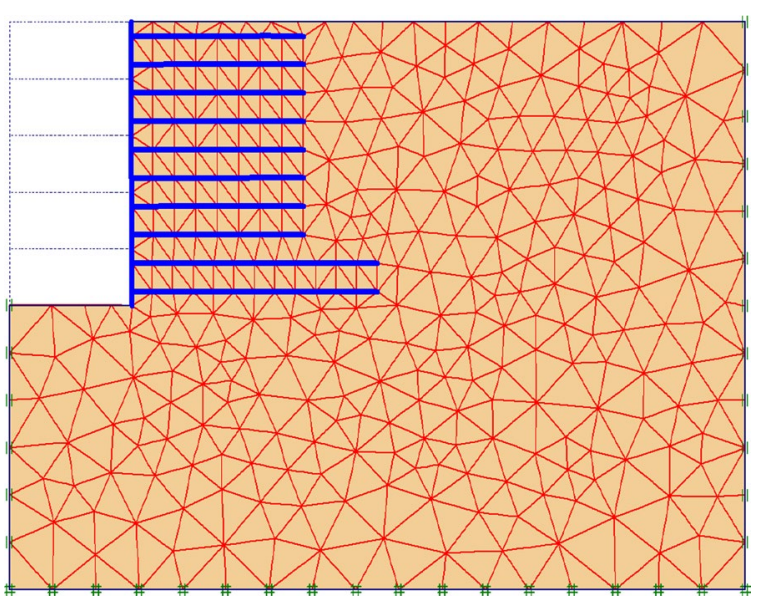

Fig. 2 Simulated soil nail wall

Table 4 Global FoS with construction stages

\begin{tabular}{lclll}
\hline $\begin{array}{l}\text { Depth of excavation } \\
\text { in meters }\end{array}$ & Construction stage \% & No. of nails & $\begin{array}{l}\text { Global factor } \\
\text { of safety }\end{array}$ \\
\cline { 4 - 5 } & & & $\frac{2}{\text { Length of nail }}$ \\
\hline 2 & 20 & 2 & 3.595 & - \\
4 & 40 & 2 & 2.353 & - \\
6 & 60 & 2 & 1.844 & - \\
8 & 80 & 2 & 1.56 & - \\
10 & 100 & 2 & 1.37 & 1.529 \\
\hline
\end{tabular}




\section{Case 2: soil without water table (WOW) having $\Theta=15^{\circ}$}

Figures 3, 4 and 5 represent the boundary conditions used in model for analyzing the dynamic behavior of the soil. At bottom total fixity is provided at sides horizontal fixity is provided since the soil is continuous in horizontal direction, the soil movement in vertical direction is allowed by curtailing it horizontally.

Nail length of $7 \mathrm{~m}$ was sufficient to have ample excavation using soil nail wall by keeping the factor of safety above 1.5. When related to case 1 it is economical to provide nails at $15^{\circ}$ inclinations then that of providing nails horizontally (Table 5).

\section{Results and discussions}

Static analysis: This work is carried out to find the impact of angle of nail inclination for the construction of soil nail wall using "PLAXIS version 8.2" is two-dimensional finite element code is used to conduct analysis of deformation and stability.

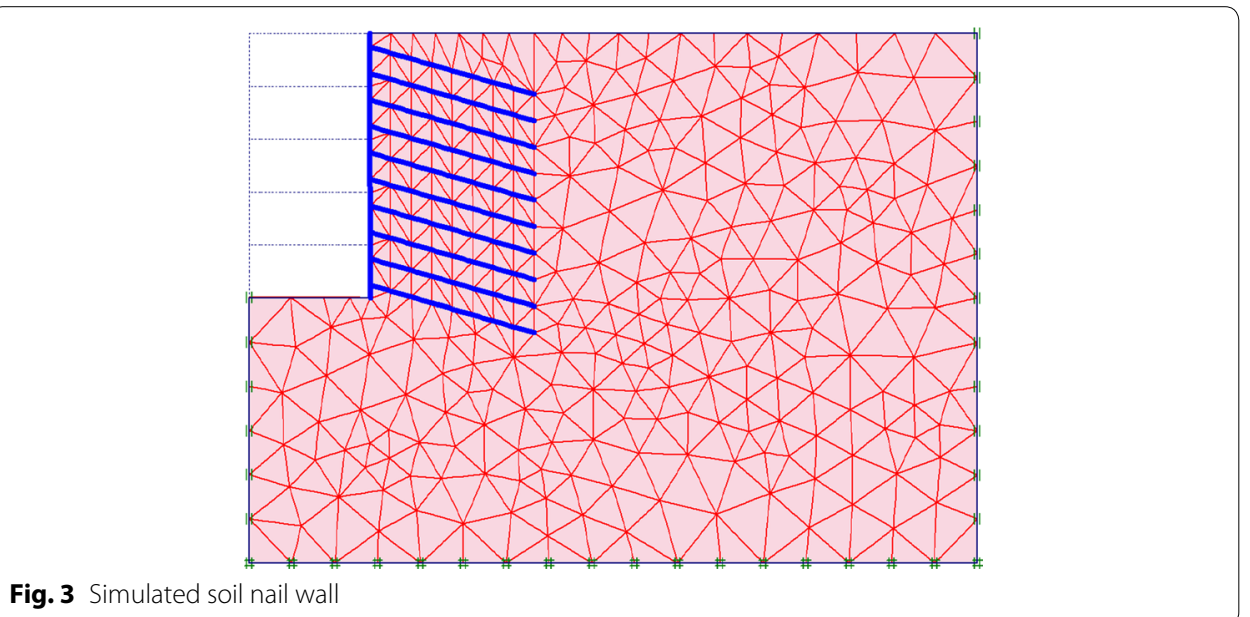

Fig. 3 Simulated soil nail wall

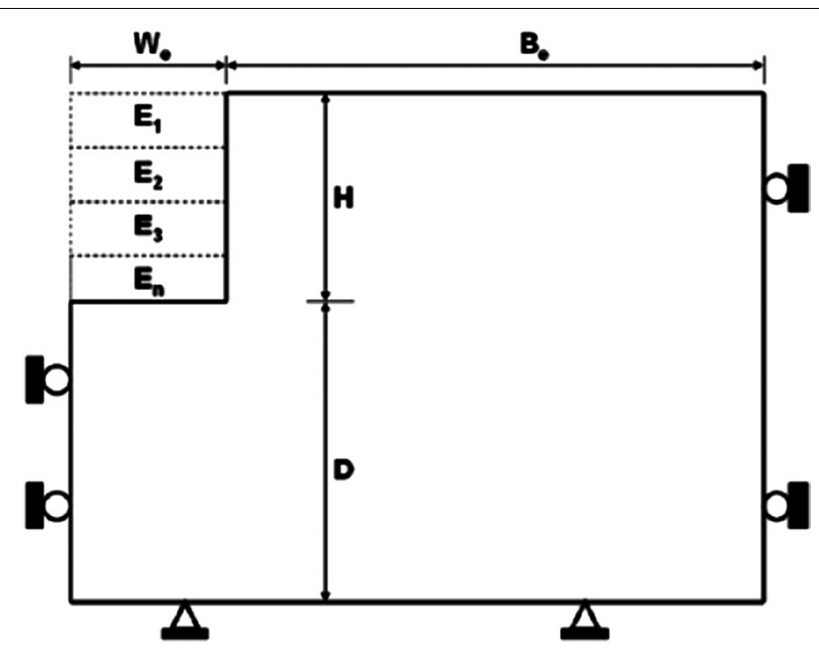

Fig. 4 Model with geometry, boundary condition and excavation stages where, $E_{1}, E_{2}, E_{3}, E_{n}$ : indicates excavation stages. $\mathrm{H}$ : total height of excavation. D: soil height below excavation. W: width of excavation. $\mathrm{B}_{\mathbf{e}}$ : horizontal distance from facing to the end of boundary 


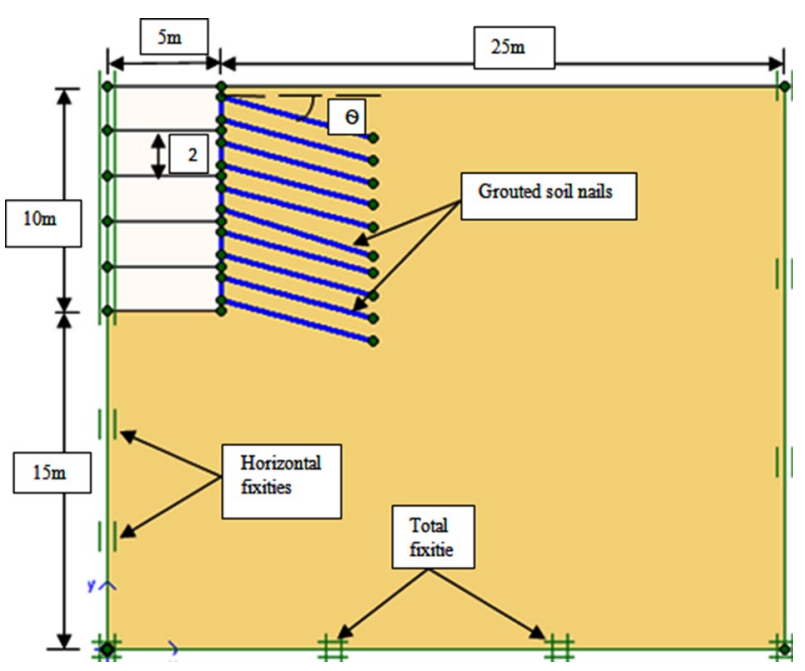

Fig. 5 Numerically simulated $10 \mathrm{~m}$ high soil nail wall

Table 5 Global FoS with construction stages

\begin{tabular}{llll}
\hline Depth of excavation in meters & Construction stage $\%$ & No. of nails & $\begin{array}{l}\text { Global factor of safety } \\
\text { Nail length 7 m }\end{array}$ \\
\hline 2 & 20 & 2 & 4.115 \\
4 & 40 & 2 & 2.714 \\
6 & 60 & 2 & 2.122 \\
8 & 80 & 2 & 1.76 \\
10 & 100 & 2 & 1.52 \\
\hline
\end{tabular}

For dynamic analysis: once the excavation is complete up to $10 \mathrm{~m}$ using soil nail wall a dynamic analysis is also carried by applying strong motion record of Upland earthquake (occurred during 20th Feb 1990 at 3.44 pm in South California)

\section{Maximum shear force in nail}

The soil mass and the movement of soil mass focuses on the soil nails to shear force in addition to axial forces [7]. The graph of maximum shear force verses the construction stages obtained is as shown below (Fig. 6).

It is perceived that the maximum shear force for $\Theta=0^{\circ}$ inclination is less for WOW, whereas it is maximum for $\Theta=15^{\circ}$. In WOW condition the maximum shear force value for $\Theta=0^{\circ}$ inclination is higher than $\Theta=15^{\circ}$ for $20 \%$ construction stage and later it decrease by from 40 to $100 \%$ construction stage.

\section{Maximum bending moment in nail}

The movement of soil mass and the soil mass subjects the soil nails to bending moment and shear force in addition to axial forces.

It is perceived from Fig. 7, that the maximum bending moment occur for $\Theta=15^{\circ}$ whereas minimum bending moment occur in both cases for $\Theta=0^{\circ}$. 


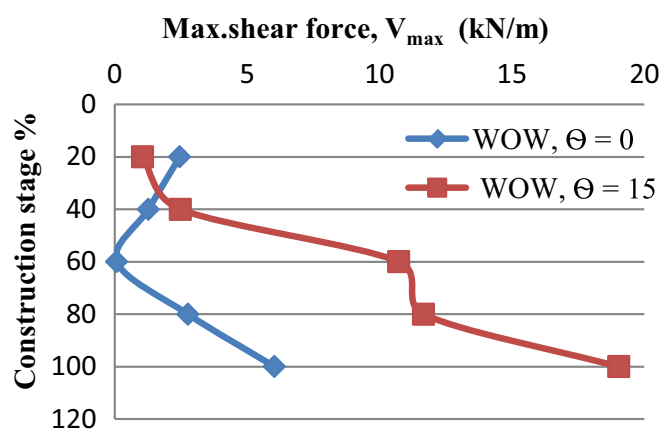

Fig. 6 With construction stage

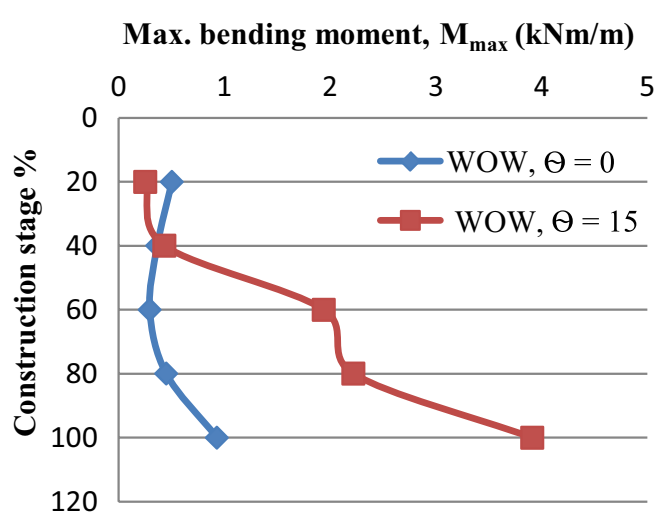

Fig. 7 With construction stage

\section{Static and dynamic analysis comparison}

After $100 \%$ accomplishment of construction stage dynamic analysis is carried out along with the static analysis. For both static and dynamic analysis, the maximum horizontal nail displacements and maximum axial force in each nail is intrigued (Fig. 8). For dynamic analysis, strong motion record of Upland earthquake is used.

\section{Maximum horizontal displacement in nails}

The maximum displacement occurs at the top of the soil. From Fig. 9, it is observed that the nails with $\Theta=0^{\circ}$ gives a lesser displacement than that of $\Theta=15^{\circ}$, this is because that the nails length were increased in case of $\Theta=0^{\circ}$ so as to increase the global factor of safety. Also, the maximum displacement occurs at the top of the soil. Fig. 10, shows the horizontal displacement of nail for dynamic condition, it is observed from the fig that nails at $\Theta=0^{\circ}$ gives a lesser displacement then $\Theta=15^{\circ}$ because of variation of nail length provided as the depth increases.

\section{Maximum axial force in nails}

From above figure, it is observed that axial force in the nail are maximum in dynamic condition compared to static. The values for both inclination of nails are approximately equal in both cases. The pattern of curve obtained for $0^{\circ}$ is same in both static and dynamic condition while the value of axial force is maximum for dynamic condition 


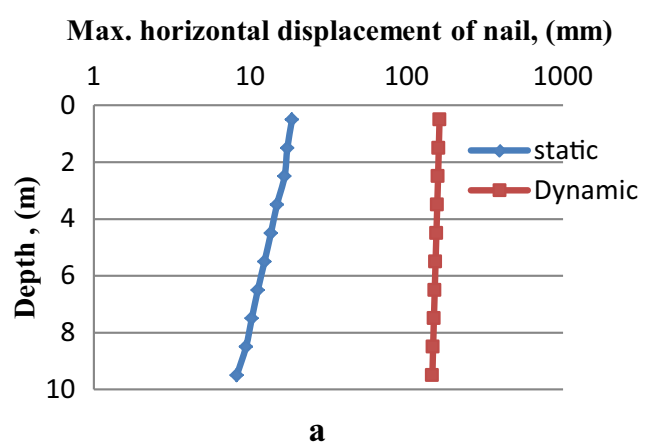

Max. horizontal displacement of nail, (mm)

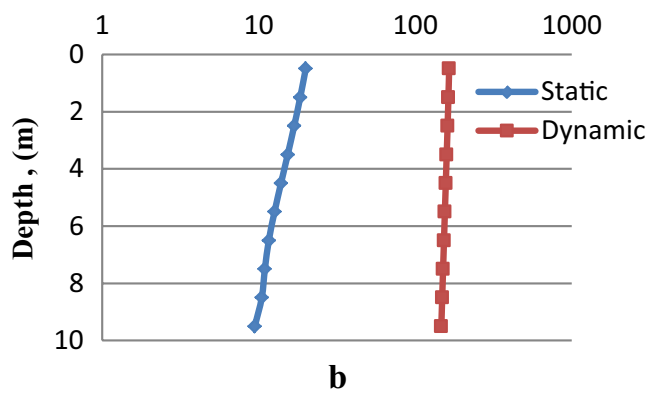

Fig. 8 Maximum horizontal nail displacement $\mathrm{v} / \mathrm{s}$ depth. a For $\boldsymbol{\Theta}=0^{\circ}, \mathbf{b}$ For $\boldsymbol{\Theta}=15^{\circ}$

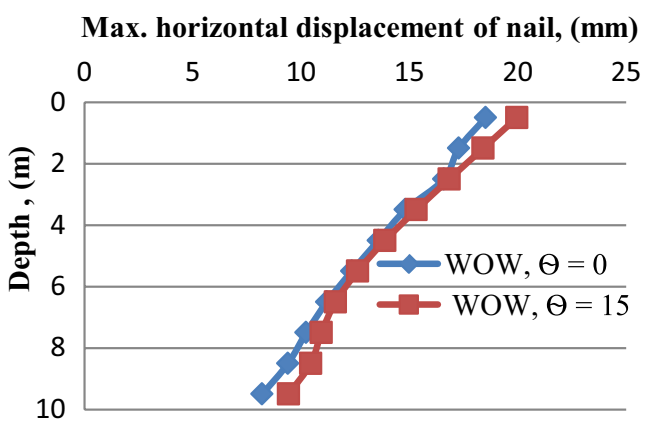

Fig. 9 Soil under static condition

compared to soil under static condition (Fig. 11). Also the outline of curve is same for $15^{\circ}$ nail inclination in both cases and maximum value under dynamic condition compared to static condition.

\section{Conclusions}

1. The length of nail has a major impact on the behavior of soil nail wall system.

2. Increase in nail length will increase the Global factor of safety $\left(\mathrm{FS}_{\mathrm{G}}\right)$ to certain degree.

3. As the depth of excavation increases the displacement of soil nail wall too increases. 


\section{Max. horizontal displacement of nail, (mm)}

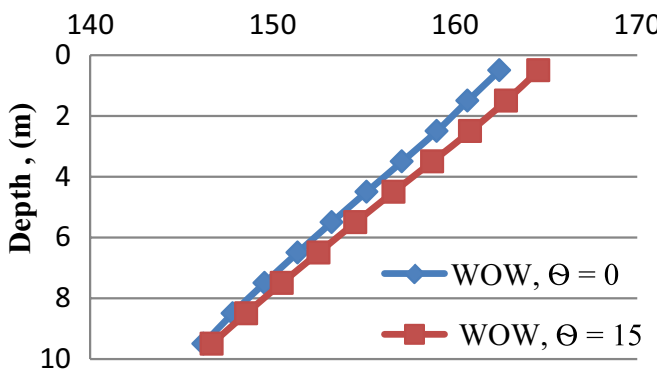

Fig. 10 Soil under dynamic condition

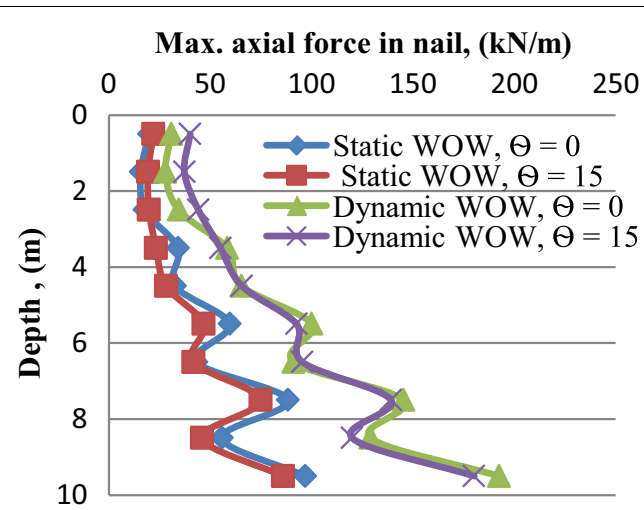

Fig. 11 For static condition and dynamic condition

4. It can be seen that the displacement of wall for nail inclination at $\Theta=0^{\circ}$ is less than $\Theta=15^{\circ}$ up to a depth of $4 \mathrm{~m}$.

5. The displacement increases for $\Theta=0^{\circ}$ from 4 to $10 \mathrm{~m}$ when compared to nails at $\Theta=15^{\circ}$. Hence soil nails inclined at $\Theta=0^{\circ}$ is suitable for shallow depths.

6. It can be seen that the maximum displacement of the soil without water table condition should have lesser displacement.

7. It is also seen that there is not much different in the displacement since the nail length is increased to achieve the global factor of safety above 1.5.

8. The maximum displacement of wall is found at the top in both static and seismic circumstances.

\section{Author details}

${ }^{1}$ Department of Civil Engineering, Bheemanna Khandre Institute of Technology, Bhalki, India. ${ }^{2}$ Department of Civil Engineering, Don Bosco Institute of Technology, Bangalore, India. ${ }^{3}$ Department of Civil Engineering, University Visvesvaraya College of Engineering, Bangalore University, Bangalore, India.

Received: 19 August 2016 Accepted: 28 September 2016

Published online: 07 October 2016 


\section{References}

1. Shaw-Shong L (2005) Soil nailing for slope strengthening. Gue \& Partners Sdn Bhd, Kuala Lumpur, pp 1-19

2. Gurpersaud N, Vanapalli S, Sivathayalan S (2013) Semiempirical method for estimation of pullout capacity of grouted soil nails in saturated and unsaturated soil environments. J Geotech Geoenviron Eng 139(11):1-8

3. Chen CS et al (2004) Failure of soil nail slopes. 15th Southeast Asian Geotechnical Society, Thailand, pp 22-26

4. Jones AMC, Davies MCR (2000) A investigation of long term stability of a soil nailed excavation using centrifuge modelling, Proceeding. 12WCEE, Auckland

5. Akhavan Mehran et al (2011) Comparing the result of numerical analysis and monitoring about the behaviour of cracks occurred near by soil nail walls. EJGE 16:1239-1252

6. Elias V, Juran I (1991) Soil nailing for stabilization of highway slopes and excavation report FHWA-RD-89-198. Federal Highway Administration, Department of transportation, Washington

7. Siva Kumar Babu GL et al (2008) Numerical analysis of performance of soil nail walls in seismic conditions. ISET J Earthquake Technol 45:31-40

8. Jacobsz SW (2013) Centrifuge modelling of a soil nail retaining wall. J South Afr Inst Civil Eng 55:85-93

\section{Submit your manuscript to a SpringerOpen ${ }^{\circ}$} journal and benefit from:

- Convenient online submission

\section{Rigorous peer review}

- Immediate publication on acceptance

Open access: articles freely available online

- High visibility within the field

- Retaining the copyright to your article 